\title{
THE SLOW RELEASE OF BMP-7 AT A LOW DOSE ACCELERATES DENTAL IMPLANT HEALING IN AN OSTEOPENIC ENVIRONMENT
}

\author{
E.B. Hunziker ${ }^{1, *}$, Y. Liu ${ }^{2}$, M. Muff ${ }^{1}$, T. Haegi ${ }^{1}$, N. Shintani ${ }^{3}$ and K. Lippuner ${ }^{3}$ \\ ${ }^{1}$ Departments of Osteoporosis and Orthopaedic Surgery, Inselspital Bern, University Hospital, \\ Bern, Switzerland \\ ${ }^{2}$ Department of Oral Implantology and Prosthetic Dentistry, Academic Centre for Dentistry Amsterdam \\ (ACTA), VU University, Amsterdam, the Netherlands \\ ${ }^{3}$ Department of Osteoporosis, Inselspital Bern University Hospital, University of Bern, Bern, Switzerland
}

\begin{abstract}
The aim of the present study was to investigate in vivo whether bone morphogenetic protein-7 (BMP-7) was able to promote and accelerate dental implant healing at a low dose in an osteopenic environment by using a delayed drug-release system.

Skeletally mature Chinese goats, having physiologically osteopenic (osteoporotic-like) facial bones, served as an animal model. Dental implants were provided with a delayed-release drug-delivery system and BMP-7 was applied at three different dosages. The implants, inserted into healed extraction sockets, were removed 1, 2 and 3 weeks after surgery. Quantification of osseointegration and formation of new bone in the periimplant space were measured histomorphometrically.

Data revealed no evidence of any adverse drug effect at or near the implantation sites. After the first postoperative week, bone neoformation was minimal; after the second week, peri-implant bone formation appeared, particularly in the groups with low dosages of BMP-7. After 3 weeks, new-bone volume was the largest in the group with the lowest (near-physiological) dosage of BMP-7, also showing the highest efficacy of BMP-7. Other dosage or release modes were found to be significantly less effective.

BMP-7 was highly efficacious in promoting and accelerating bone formation in the peri-implant space in a hostile osteopenic environment if released by a slow-mode mechanism over time at near physiological activities. Therefore, biological functionalisation of dental implants by a high-power osteogenic factor may improve their healing success in hostile bony environments (osteopenia, osteoporosis, bone atrophy etc.).
\end{abstract}

Keywords: Dental implant healing, osteopenia, osteoporosis, osteoinduction, bone morphogenetic protein-7, slow-release system, improved safety, enhanced efficacy.

*Address for correspondence: E.B. Hunziker, MD, PhD, Departments of Osteoporosis and Orthopaedic Surgery, Inselspital Bern University Hospital, Freiburgstrasse 3, CH-3010 Bern, Switzerland.

Telephone number: +41 794446551 Email: ernst.hunziker@dbmr.unibe.ch

Copyright policy: This article is distributed in accordance with Creative Commons Attribution Licence (http://creativecommons.org/licenses/by-sa/4.0/).

\section{Introduction}

Dental implantology has developed quite rapidly during the past decades into a very successful clinical field. It was able to significantly improve patient life quality in all age groups (including the elderly) by providing safe and reproducible treatment schemes for a large variety of patients, thus becoming a widely used treatment both in dental traumatology as well as in a large variety of disease-associated tooth loss conditions (Ananth et al., 2015; Bohner et al., 2019; Pauletto et al., 2019). A large group of patients, in particular those with insufficient oral hygiene and with associated parodontitis problems, is considered at high risk of implant failure (Hasanoglu Erbasar et al., 2019; Pirc and Dragan, 2017). However, these patients can still be treated, provided that adequate instruction of patients is assured and that there is reasonable patient compliance. But there remain large patient groups that are confronted with higher failure risks of these treatment approaches, mainly due to problems associated with local lack of bone tissue [osteoporosis, osteopenia, atrophy (Bertl et al., 2015; Radi et al., 2018)], Paget-related metabolic bone disorders (Alonso et al., 2017; Hammerle and Tarnow, 2018) and also those suffering from impaired bloodvessel formation problems [reduced angiogenesis activities (Pearl and Kanat, 1988)]. Another group of patients that are generally excluded from implant treatment are those subject to some specific medical 
treatments [chemotherapy, radiation therapy, etc. (Chen et al., 2013; Kullar and Miller, 2019)], that suffer from diseases such as diabetes (Jude et al., 2010; Naujokat et al., 2016) or that practice nicotine abuse (Hasanoglu Erbasar et al., 2019; Kullar and Miller, 2019). Patients with such pathologies are considered at high-risk for implant therapy (Naujokat et al., 2016) and are, thus, often excluded from the beneficial implant-related therapeutic treatments, simply since bone-forming/healing capabilities are insufficient (Hammerle and Tarnow, 2018; Kullar and Miller, 2019; Obalum et al., 2013) under such conditions.

The study hypothesis was that if implants were placed under such adverse biological conditions, in particular under local osteopenic (or osteoporotic) conditions, but together with a powerful osteoinductive drug (Nam et al., 2017; Shim et al., 2018), this would be able to locally overcome such healing limitations and actively promote angiogenesis (Benn et al., 2017; Pearson et al., 2019) and bone formation. In this way, such high-risk patients could be converted into low-risk patients and more individuals could benefit from the advantages of dental implants. If this were the case, then the scope of indications for implant treatment could be widened.

A group of drugs that can help overcome such biological implant-healing limitations are the bone morphogenetic proteins (BMPs) (de Queiroz Fernandes et al., 2018; Krishnakumar et al., 2017) that both have an angiogenic (Benn et al., 2017; Pearson et al., 2019) and osteogenic potential, i.e. are able to actively promote bone formation and angiogenesis. BMPs, such as BMP-2, are already in clinical use in medicine for the treatment of spinal disorders as well as impaired fracture healing (non-unions) and have led to very successful treatment results (de Queiroz Fernandes et al., 2018; Krishnakumar et al., 2017). The clinical use of BMPs carries several potential risks, leading to drug-induced problems (Bodalia et al., 2016; Faundez et al., 2016). Such risks are related to their use in a free form, in which they are exposed locally to many different cell populations (unrelated to bone formation) present in the body. This is particularly the case when their therapeutic use is not restricted, in a more focused application-mode, to the specifically targeted cell populations that are involved with bone formation and angiogenesis processes. Moreover, they are currently used at very high dosages, being able, given their pleomorphic nature (common to many growth factors), to elicit opposite effects depending on the concentration at which they reach the target cells (James et al., 2016). Given such undesired effects, several slow drugrelease systems have been developed and applied for BMPs to reduce the concentrations of the drug and to prolong its effects in time (Gruber et al., 2009; Liu et al., 2006a; Maisani et al., 2018; Teng et al., 2019; Venkatesan et al., 2019). The present study used a BMP confined in a carrier that prevented the interaction with unintentionally targeted cell populations, thus mimicking the growth-factor-containing mineralised bone matrix compartment (Hauschka et al., 1988; Hauschka et al., 1986; Linkhart et al., 1996). This enabled BMP to be exposed only to the desired cell populations specifically involved in bone induction activities. Moreover, BMP was applied at a very low (i.e. physiological-like) concentration to overcome its many undesired effects. For this purpose, a slow drug-release system that simulated mineralised bone matrix was used as a drug carrier, with the drug incorporated at a physiological-like concentration. To test this hypothesis, an experimental animal model with physiological osteopenic mandibulae and maxillae (as a paradigm for osteoporotic and other types of structural bone deficiencies) in the masticatory apparatus was used.

\section{Materials and Methods}

\section{Experimental design}

The aim of the present study was to elucidate if BMP-7, used in a confined compartment of a slow drug-release system and at low concentration, was able to enhance bone formation around dental implants and accelerate their osseointegration in an osteopenic environment. For this purpose, a recently developed experimental implant type was used (Hunziker et al., 2018) that allows for quantitative bone formation assessment and osseointegration over time of bioactive implant-surfaces. Acid-etched and sand-blasted titanium implants were used and coated with a calcium phosphate $(\mathrm{CaP})$-based slow-release system. The implants had large periimplant chambers (Fig. 1) to be filled with new bone. The implants were inserted into the edentulate maxillae of adult goats that characteristically have physiologically (inherent to this animal, i.e. not experimentally induced) osteopenic bones of the masticatory apparatus (Caulier et al., 1997). A physiological model of osteoporosis was chosen to avoid secondary, experimentally induced bone formation problems (He et al., 2011). 48 goats were used and 3 different post-operative time points analysed (i.e. 1, 2 and 3 weeks after surgery) for a total of 54 implants placed per time point (i.e. 4 implants per animal; Table 1). The implants with surrounding bone tissue were excised after surgery for histomorphometrical analysis of pertinent stereological estimators, namely, the volume of neo-formed bone within the chamber space of the implant and the bone-to-implant contact (BIC) area. During specimen excision, the surrounding hard and soft tissues in the immediate vicinity and at larger distances were carefully inspected and checked for untoward effects such as cyst formation and ectopic ossification (James et al., 2016).

\section{Experimental implant}

The titanium single-chamber experimental dental implants were designed and manufactured according 
to a recent study (Hunziker et al., 2018). The single cylindrical chamber was $2.1 \mathrm{~mm}$ in diameter, $1.3 \mathrm{~mm}$ in depth (Fig. 1). Thus, the chamber diameter approached the critical dimensions for bone-toimplant gap healing, the critical size [i.e. the chamber dimensions were larger than what would allow spontaneous bone-to-implant bridging by new bone and, thus, spontaneous bony integration in vivo was prevented (Botticelli et al., 2003; Harris et al., 1983; Hunziker et al., 2018)].

\section{Experimental groups}

8 experimental groups were established (Table 1), each one consisting of 6 animals. Groups 1, 2 and 3 comprised titanium implants with standard sandblasted, acid-etched chamber surfaces and were biomimetically coated with the electrolyte-based drug-release system (Liu et al., 2006b). The coatingcarrier material contained incorporated BMP-7 at high (group 1), middle (group 2) and low (group 3) concentrations. In groups 4, 5 and 6, the sand-blasted, acid-etched chamber surface was biomimetically coated with the drug-release material in the absence of BMP-7. Then, BMP-7 was secondarily adsorbed to this coating surface at a high (group 4), middle (group 5) or low (group 6) concentration (Hunziker et al., 2016). Group 7 implants were biomimetically coated with the release system, but no BMP-7 was added; group 8 was left uncoated and no BMP-7 was added. Each animal received 4 implants according to a systematic random distribution protocol; thus, per experimental group and per time point 24 and 8 implants were used, respectively. This resulted in a total of 192 implants for the whole experiment, comprising a total of 48 animals.

\section{Biomimetic-coating-release system}

The implant biomimetic coating was modified to function as a drug-release system by depositing a bi-layer of electrolytes on the implant surfaces, as previously described (Liu et al., 2006b). Briefly, the implants were immersed for $24 \mathrm{~h}$ at $37^{\circ} \mathrm{C}$ in concentrated simulated body fluid (Liu et al., 2006b) under high-nucleation conditions to inhibit crystal growth. The thin (1-3 $\mu$ m-thick) initial layer of amorphous $\mathrm{CaP}$ deposited on the implant surface served as a seeding substratum for the subsequent deposition of a thicker layer (35-40 $\mu \mathrm{m}$ thick) of crystalline $\mathrm{CaP}$, which served as the drug carrier and release system. This second layer was prepared by immersing the implants for $48 \mathrm{~h}$ at $37^{\circ} \mathrm{C}$ in a supersaturated solution of TRIS-buffered (50 mmol/L; pH 7.4) CaP ions, containing the desired concentrations of BMP-7 (see below) for co-precipitation. The entire coating procedure was conducted under sterile conditions.

\section{BMP-7: incorporation, quantification and efficacy} computation

Human recombinant BMP-7 [also called OP-1 (Gothard et al., 2014; Kowalczewski and Saul, 2018)] was used. The material was obtained as a generous gift from the previous Stryker Biotec Corporation (a previous subsidiary of the Stryker Corporation, Mahwah, NJ, USA). BMP-7 was added to the coating solutions at a low, middle and high concentration $(0.1 \mu \mathrm{g} / \mathrm{mL}, 11 \mu \mathrm{g} / \mathrm{mL}$ and $101 \mu \mathrm{g} / \mathrm{mL})$ such that BMP-7 total amount per implant after completion of implant coating resulted in $0.23 \mu \mathrm{g}, 4.54 \mu \mathrm{g}$ and $17.9 \mu \mathrm{g}$, respectively. The quantitative values of these carrier-incorporated BMP-7 amounts were obtained by using tritium-labelled BMP-7 and subsequent quantification of radioactivity after dissolution of the carrier coatings obtained by the three different concentrations of BMP-7 in the coating solutions (Table 1). The adsorbed amounts of BMP-7 were obtained by adsorbing defined amounts of BMP-7 solution to the implant surface and letting them dry onto the surface in a sterile hood, such that comparable total amounts of adsorbed BMP-7 were a

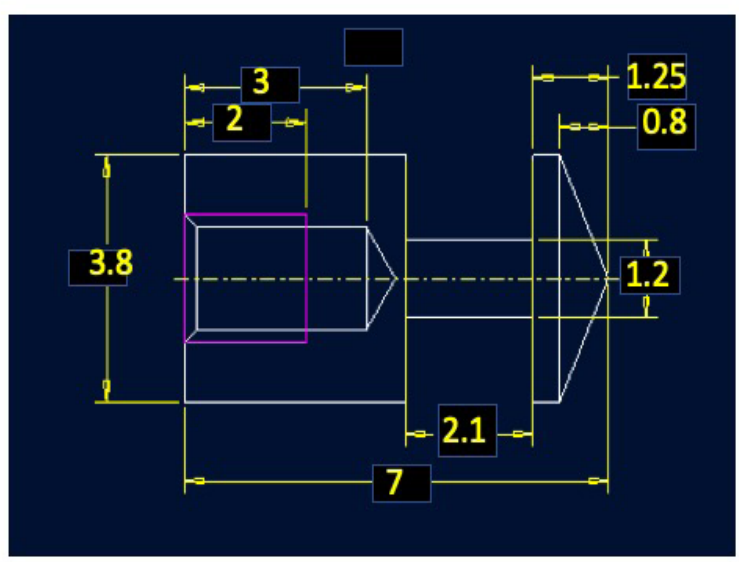

b

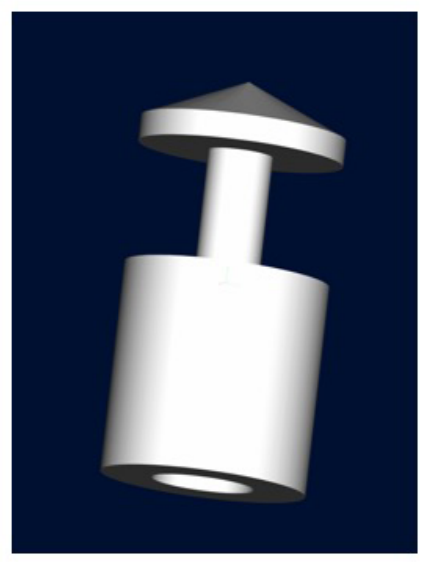

Fig. 1. Illustration of the experimental dental implant used. (a) Longitudinal section through the implant; dimensions are indicated in $\mathrm{mm}$. (b) Image of the implant, illustrating its cylindrical shape, with the large single bone chamber for the testing of the osteogenic activity. 
Table 1. Experimental groups.

\begin{tabular}{|c|c|c|c|c|}
\hline \multirow{2}{*}{ Groups } & Coating & \multicolumn{3}{|c|}{ BMP-7 } \\
\cline { 2 - 5 } & Presence (+)/absence (-) & Presence (+)/absence (-) & Concentration & Mode of use \\
\hline $\mathbf{1}$ & + & + & High & Incorporated \\
\hline $\mathbf{2}$ & + & + & Middle & Incorporated \\
\hline $\mathbf{3}$ & + & + & Low & Incorporated \\
\hline $\mathbf{4}$ & + & + & High & Adsorbed \\
\hline $\mathbf{5}$ & + & + & Middle & Adsorbed \\
\hline $\mathbf{6}$ & + & + & Low & Adsorbed \\
\hline $\mathbf{7}$ & + & - & - & - \\
\hline $\mathbf{8}$ & - & - & - & - \\
\hline
\end{tabular}

obtained per implant $(0.5 \mu \mathrm{g}, 5 \mu \mathrm{g}$ and $15 \mu \mathrm{g}$; Table 2) in the adsorbed BMP-groups.

The concentration of BMP-7/g coating material was assessed by measuring the total amount of BMP-7 incorporated per implant (using a group of 6 samples) and the carrier (coating) weight per implant, measured by weighing the implants after coating and again after removal of the coating to obtain the total average weight of coating (carrier) material per implant. These data delivered the basis for the calculations of BMP-7 concentration in the coating material. The results obtained were as follows: $29.9 \mu \mathrm{g}$ BMP-7/g coating material (low-dose group), $591.1 \mu \mathrm{g}$ BMP-7/g coating material (middle-dose group) and 2,330 $\mu \mathrm{g} / \mathrm{g}$ coating material (high-dose group). The average weight of the coating/implant was $7.68 \pm 0.54$ $\mathrm{mg}$ [ $n=12$ implants for coating (carrier) weight].

In a previous study relating to the coating technology, Liu et al. (2006b) determined that the incorporation of a growth factor (or a protein, such as albumin) leads to a homogenous distribution of the compound throughout the coating material, i.e. throughout the drug-release system material. On this basis, the extent of the coating degradation during the experiment when measured at the different time points could be used to determine how much BMP-7 was released during the degradation activity and how much was still incorporated in the remaining coating volumes. The remaining coating thickness was measured at each experimental time point analysed and, thus, the amount of BMP-7 liberated during each time span of the experiment was determined. The information provided yielded the basis for the determination of BMP-7 efficacy, i.e. how much bone volume was generated per $\mu \mathrm{g}$ of liberated (and thus consumed) BMP-7. The calculated BMP-7 efficacy values, obtained on this basis, are presented in the Results section.

\section{Experimental animals and surgery}

A total of 48 adult (2-3 years old) goats, which physiologically have osteopenic masticatory bones (Caulier et al., 1997), were used. 3 months prior to implant placements, 3 left and 3 right premolars were surgically extracted from the maxillae of the animals. $10 \mathrm{~min}$ before surgery, general anaesthesia was induced by an intramuscular injection of xylazine (20 mg/mL: $0.22 \mathrm{mg} / \mathrm{kg}$ of body weight; Lanzhou Zhengfeng Pharmaceutical Co. Ltd, Lanzhou, China). Then, local anaesthesia of the maxillary sites was induced with an injection of lidocaine $(20 \mathrm{mg} / \mathrm{mL}$ : $0.83-1.25 \mathrm{mg} / \mathrm{kg}$ of body weight in $2.5 \mathrm{~mL}$; Shandong Yinhu Pharmaceutical Co. Ltd, Shandong, China). After surgically extracting 3 left and 3 right premolars from the maxillae of the animals, an intramuscular injection of atipamezole (an inhibitor of the $\alpha-2$ receptor) (5 mg/mL: $100 \mu \mathrm{g} / \mathrm{kg}$ of body weight; Zoetis China, Shanghai, China) was administered to accelerate the termination of anaesthesia. At the time of surgery and $3 \mathrm{~d}$ later, the animals received an intramuscular injection of benzylpenicillin (150,000 IU/mL: $0.1 \mathrm{~mL} / \mathrm{kg}$ of body weight; maximally 5 mL/goat; Hubai Pharmaceutical Co. Ltd., Hubei, China). During the first 3 post-operative days, analgesics (1 mg/kg Flunixin, Hangzhou Huadi Group Co., Ltd., Zhejiang, China) were administered.

3 months were allowed for the healing of the extraction sockets. Then, the implants were inserted under the same conditions of general and local anaesthesia (as described above). 4 implants were inserted into the maxilla ( 2 on the left side and 2 on the right side) of each animal according to a systematic random protocol. To assure mutual independence of the implantation sites, each implant was separated from its neighbours by a minimal distance of $2 \mathrm{~mm}$. The implants were inserted according to a standard surgical procedure. Intra- and post-operatively, the animals were treated as they had been during the tooth-extraction procedure (see above). After surgery, and up to the time of sacrifice, they were housed at a local farm and fed standard goat's food (forages, grains, hay, browse and shrub plants; Web ref. 1). The animals were euthanised under general anaesthesia by administering an overdose of $\mathrm{KCl}$, which induced cardiac arrest.

The study was approved by the Commission for Animal Experimentation of the State of Bern (Switzerland) as well as the Ethics Committee of the 
Table 2. BMP-7 dosages and mode of delivery: incorporated (inc.) or adsorbed (ads.) Average coating weight: $7.68 \pm 0.54 \mathrm{mg}(n=12)$.

\begin{tabular}{|c|c|c|}
\hline Delivery mode/dosage & BMP-7 per Implant $(\boldsymbol{\mu g})$ & $\boldsymbol{\mu g}$ BMP-7/g coating \\
\hline Inc./High BMP-7 & 17.9 & 2330.7 \\
\hline Inc./Middle BMP-7 & 4.54 & 591.1 \\
\hline Inc./Low BMP-7 & 0.23 & 29.9 \\
\hline Ads./High BMP-7 & 15 & 1953.1 \\
\hline Ads./Middle BMP-7 & 5 & 651.0 \\
\hline Ads./Low BMP-7 & 0.5 & 65.1 \\
\hline CaP-coating alone & 0 & 0 \\
\hline
\end{tabular}

Inner Mongolia Agriculture University (China). It was conducted in accordance with the EU Directive 2010/63/EU on protection of animals used for scientific purposes, the ARRIVE guidelines and the UK Animals Act (Scientific Procedures) 1986.

\section{Histological processing and sampling}

The maxilla of each animal was bisected into its left and right halves using a Stryker Orthopaedics saw. The soft tissues were removed and excess bone around the implants was cut away using an Exakt saw (Exakt, Norderstedt near Hamburg, Germany). In the mesiodistal direction each tissue block extended either to the neighbouring tooth or to the middle between the implants. In the buccolingual direction the surrounding tissues were included up to the natural borders of the mandibula/maxilla. Then, the implants were chemically fixed in $4 \%$ formaldehyde solution for $10 \mathrm{~d}$ at ambient temperature. After rinsing in tap water, they were separated from each other by using an Exakt saw. The individual implants were dehydrated in ethanol and embedded in methylmethacrylate, as previously described (Hunziker et al., 2007; 2018). Using a Leica saw (Leica Microsystems), each implant was sectioned in directions that run parallel to its longitudinal axis and according to a systematic random sampling protocol (Gundersen and Jensen, 1987). Each block of methylmethacrylate was cut twice parallel to its longitudinal axis at the centre of the implant, with a separation distance of $250 \mu \mathrm{m}$. Then, the approximately $300 \mu \mathrm{m}$-thick slices thereby produced were cut at right angles to the longitudinal axis of the implant. Subsequently, the axial sawing direction for the remaining implants was systematically changed in increments of $30^{\circ}$ such that the orientation of the saw-cuts ranged between the mesiodistal and the buccolingual directions. Next, the $\approx 300 \mu$ m-thick saw-cuts were mounted on plexiglass holders, polished down to a thickness of about $100 \mu \mathrm{m}$ and surface-stained with basic fuchsin, toluidine blue and McNeal's tetrachrome (Hunziker et al., 2007).

\section{Light microscopy and histomorphometry}

The stained saw-cuts were examined using a Nikon Eclipse E1000 light microscope (Nikon). If there was any evidence of local infection, inflammatory activity or a technical artifact in a specimen, it was discarded. Primary stability of an implant was a pre-condition for its histomorphometric analysis. Sufficient primary stability was defined as the existence of minimally three points of firm implant anchorage within solid native bone. Anchorage within connective tissue was considered to be indicative of mechanical instability. External to the implant chamber (Fig. 2), the region that embraced the interface between the implant and the native bone bed was not analysed.

The peripheral vertical boundary of the implant chamber was defined by a virtual, idealised line that connected the shoulders of the crestal and the apical walls and that ran parallel to the central vertical wall (Fig. 2). The boundary between the central vertical wall of the chamber and the crestal or the apical walls was defined by the point of their intersection, with a virtual line that bisected the central corners of the chamber at an angle of $45^{\circ}$ relative to each face.

For the evaluation of the BIC-area density along the bone chamber surface, the inner chamber surface (i.e. the implant chamber space distant from the native bone where osteoinduction activity is required to form new bone tissue) (Fig. 2b) was analysed. BIC was measured using a grid of parallel vertical test-lines, which were separated by a fixed distance of $2 \mathrm{~mm}$, and by counting the intersection points of the test lines hitting bone-implant surface interaction areas.

The volume density of neoformed mineralised bone within the chamber was estimated using the point-counting technique (Gundersen et al., 1988). Briefly, a grid (intersecting vertical and horizontal lines with equal distances from each other) on a transparent foil was superimposed on the printed histological images. Then, the grid points hitting bone tissue versus grid points in the total implant chamber space were counted. Next, the quotient of the two values represented the estimator for bone volume density. The thickness of the remaining coating release system was measured by using a set of parallel lines, fixed distances apart, and placing them perpendicularly to the implant surface with a random starting point. The remaining coating thickness was measured along the various parallel lines. The original coating thickness generated by use of the standard chemical coating protocol was measured at time point 0 before implantation by using 8 implants that were coated by the standard protocol and then immediately processed histologically for the measurement of the original coating thickness. 


\section{Statistical analysis}

Data are presented as mean values \pm standard error of the mean (SEM). Differences between estimators of experimental groups and time points were evaluated by one-way ANOVA and by implementing Tukey's multiple-comparison test (GraphPad Prism 6, GraphPad Software). Differences between the coated and the uncoated specimens were analysed using unpaired $t$-tests. The level of significance was set at $p<0.05$.

\section{Results}

\section{Histomorphometry - new bone volume}

The focus of the data description and analysis was placed on the formation of new bone in the peri-implant chamber space and the coverage of the implant surface by new bone, since these two parameters represent the key estimators for a successful and stable osseointegration and anchoring of implants in an osteopenic environment. New bone-tissue formation in the peri-implant chamber was found to be absent (or minimal) in the first week (Fig. 3), except for the group with a low dose (0.29 ng) of adsorbed BMP-7, in which a little larger bone volume was present (but still less than $0.21 \mathrm{~mm}^{3}$; Fig. 3). Fig. 4 shows the time course of peri-implant bone volume formation by representative images of the BMP-7-incorporated groups. 1 week after surgery in the group with the lowest concentration of BMP7, no new mineralised bone tissue was present in the implant test chamber (Fig. 4a). This finding was the same for all experimental groups 1 week postoperatively (Fig. 3). However, at the end of the second week, the formation of new bone tissue was increased dramatically (Fig. 4b) and appeared to generally stabilise 3 weeks post-operatively (Fig. 4c). The groups with low $(0.02 \mathrm{ng} / \mathrm{g})$ and middle $(2.56 \mathrm{ng} / \mathrm{g})$ incorporated dosage as well as low (2.82 ng)-adsorbed dosage of BMP-7 showed significantly larger newly formed bone volumes in the peri-implant chamber space than in all the other groups (Table 2, Fig. 3). Thus, during the second week, bone deposition in the implant chamber spaces was boosted significantly, particularly in the groups in which the low and/or the intermediate dosages of BMP-7 were not only incorporated into the coating release system, but also in the one positive control group in which the intermediate dosage of BMP-7 was adsorbed onto the coating surface (Fig. 3). In the third post-operative week, the group with the lowest incorporated BMP-7 concentration showed the largest volume of newly formed bone tissue. However, bone remodelling activities appear to have started, as shown by a generally slight decrease in bone volumes at this time in several groups, with the maximum value of bone being maintained in the incorporated and in the adsorbed groups with the lowest concentrations of BMP-7 (Fig. 3). The data for bone volumes of these two groups differed significantly $(p<0.05)$ from the other groups, where no more increase in bone volume occurred. During the further healing process in the third week, it became apparent that the formation of new bone-tissue volumes plateaued for all (but one) group at around $1-1.3 \mathrm{~mm}^{3}$ of new bone in the peri-implant chamber. As expected, the variation of the results in the osteoporotic environment was relatively high, with coefficients of error values being in the order of $8-85 \%$. The one group with the highest volume of newly formed bone at the end of the third week was the one with the lowest incorporated a

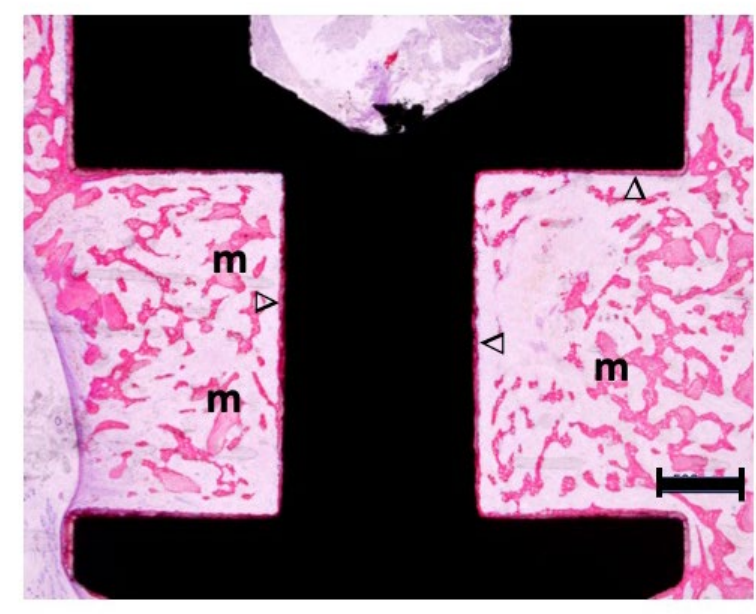

b

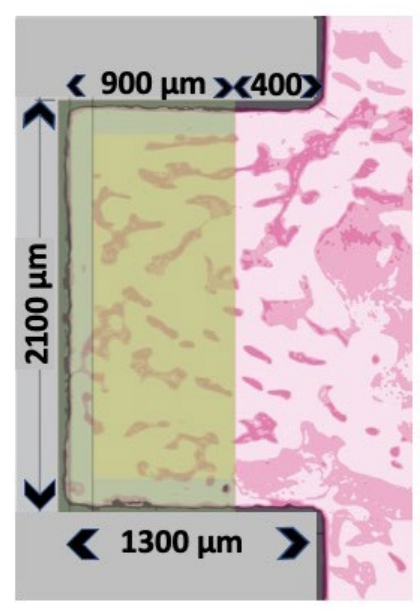

Fig. 2. Light micrographs of histological sections through an implant with a high concentration of incorporated BMP-7, three weeks after surgery. (a) The remaining thin CaP coating layer (stained in red), bearing BMP-7, could be seen along the implant surfaces $(\nabla)$. The bone chamber was thoroughly filled with new mineralised trabecular bone tissue (m) (also stained in red). Scale bar: $500 \mu \mathrm{m}$. (b) The inner part of the bone chamber was filled and delineated with a light yellow-shaded colour; it represent the dimensions of the bone chamber (given in $\mu \mathrm{m}$ ) and the area that was analysed for the quantification of the osteogenic activity. Thick sections $(80 \mu \mathrm{m})$, surface stained with McNeil's tetrachrome and acid fuchsin. 
amount of BMP-7 (0.02 ng/g coating carrier) and revealed around $1.8 \mathrm{~mm}^{3}$ of newly formed bone. This value was significantly different when compared to the implant-alone group and to the middle and high BMP-7-incorporated groups. Due to the large variances in the osteoporotic environment, the $p$-values compared to the remaining groups were in the range of $0.06-0.08$.

The groups without a CaP-coating carrier or without BMP-7 were generally found to have the smallest bone volumes (Fig. 3). Interestingly, however, the groups with higher concentrations of incorporated BMP-7 (middle and high concentrations) showed newly formed bone volumes in the same order of magnitude as those groups with BMP-7 adsorbed to the $\mathrm{CaP}$ coating carrier surface, at least 3 weeks post-operatively. 2 weeks post-operatively, the bone volumes for these groups varied considerably. It is noteworthy that the group with a CaP-coating alone without BMP-7 showed a larger bone volume than the group without any coating (metal surface: sand-blasted and acid etched) and the volume of newly formed bone of the CaP-coated group was in the same order of magnitude as the remaining BMP-7 groups.

The morphological-descriptive results of the other groups were similar, as illustrated in Fig. 4 by selected representative images.

\section{Implant surface coverage by bone (BIC)}

Newly formed bone could be identified along the chamber walls, particularly on the $\mathrm{CaP}$-coating carrier layer, which had a strong osteoconductive effect
(Fig. 5). 3 weeks after surgery, the group with the lowest incorporated BMP-7 concentration showed the highest BIC value. However, this value did not differ significantly from the adsorbed middle-concentration group ( $p>0.05)$, with the highest BIC value 2 weeks post-operatively (Fig. 5).

A particularly interesting finding was that the CaP-only group showed a bone coverage result in the order of $40 \%$, i.e. very similar to the BMP-7 groups (irrespective if adsorbed or incorporated). Moreover, the metal-surface-only group clearly showed a significantly lower BIC value when compared to all the other experimental groups (Fig. 5), both 2 and 3 weeks post-operatively.

It is noteworthy that by the end of the third postoperative week, the BIC value was the highest in the group in which the lowest dosage of BMP-7 was incorporated into the coating and in the group with the intermediate dose of surface-adsorbed BMP-7. Interestingly, the second-higher dose of adsorbed BMP-7 was associated with a significant drop in the BIC value obtained $(p<0.05)$, pointing out the critical role of BMP-7 dosage for optimal surface osteoconductive effects.

\section{BMP-7 release and efficacy}

The measurement of the coating degradation, i.e. the initial mean coating thickness minus the coating thickness at the end of the first, second and third week, revealed that in the first 2 weeks carrier coatings were degraded by about $60-70 \%$ and that the degradation process continued in the third week so that about $70-85 \%$ of the coatings became

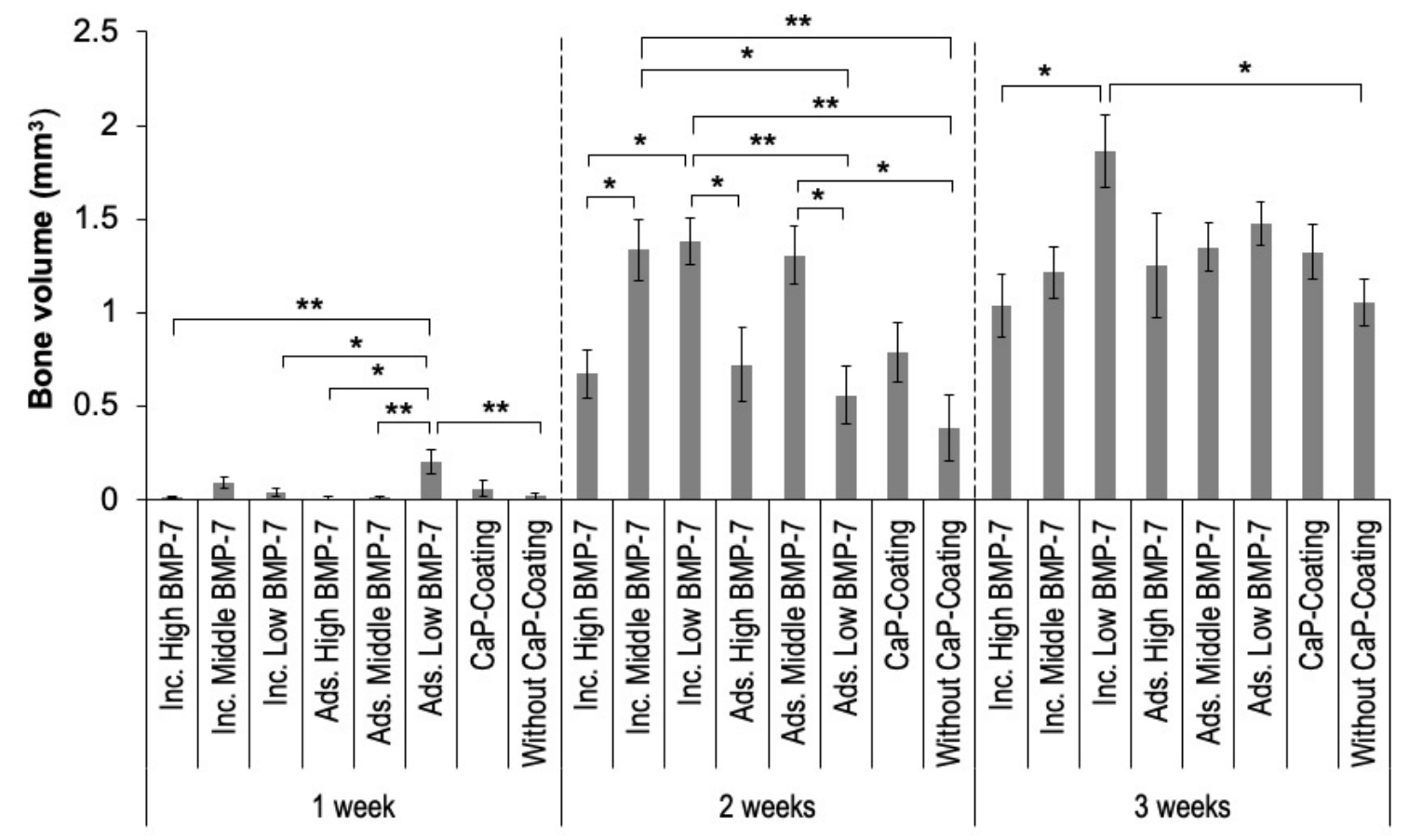

Fig. 3. Bone volumes measured in the various groups represented from the 3 time points investigated. 2 weeks after surgery, the groups with the incorporated (Inc.) middle and low BMP-7 concentrations and the one with the adsorbed (Ads.) middle concentration showed the largest amounts of new bone tissue in the bone chambers. 3 weeks after surgery, the group with the low incorporated BMP-7 concentration showed the largest newly formed bone volume. Mean values \pm SEM are shown. ${ }^{*} p<0.05,{ }^{* *} p<0.01$. 
degraded in all groups (data not shown). Based on the data obtained for coating carrier degradation and BMP-7 concentrations in the coating, BMP-7 release per time interval (first, second, third week) could be computed. The efficacy of BMP-7, which was defined as the volume of bone formed per $\mu \mathrm{g}$ of BMP-7 liberated from the coating carrier, was found to be highest in the group in which the lowest BMP-7 dosage was incorporated into the release system. This efficacy index was calculated based on the coating thickness at the end of each time period (Fig. 6). Data revealed that the efficacy of BMP-7 was clearly and significantly the highest in the group with the lowest incorporated BMP-7 concentration: in the second week, it was around $234 \mathrm{~mm}^{3}$ of new bone per $\mu \mathrm{g}$ of liberated BMP-7; in the third week, around $103 \mathrm{~mm}^{3}$ of new bone per $\mu \mathrm{g}$ of liberated BMP-7 (Fig. 6). Thus, higher BMP-7 efficacy values were achieved by its
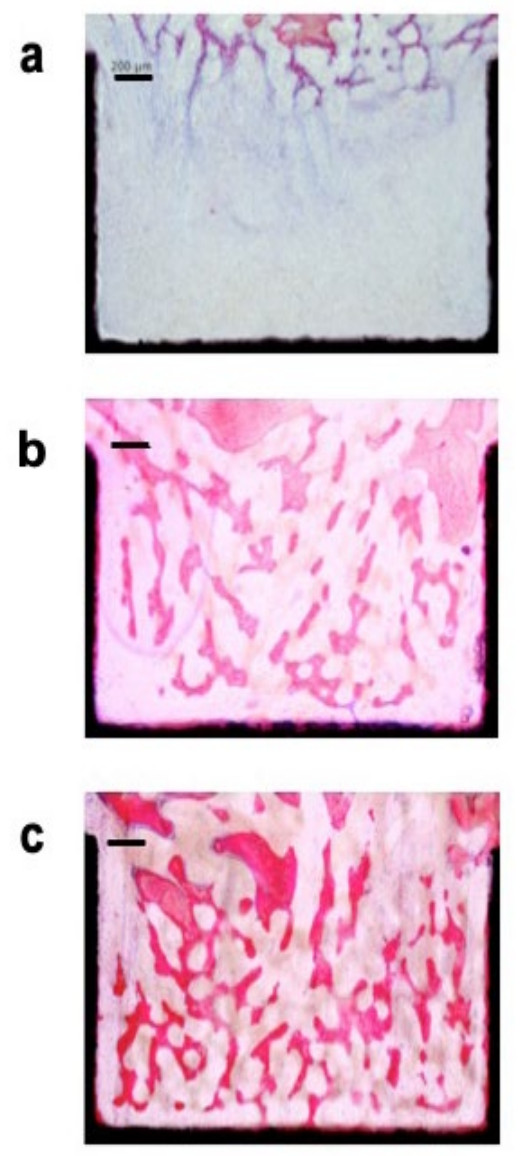

Fig. 4. Light micrograph of representative histological sections through implants from the 3 different post-operative time points investigated. (a) Adsorbed middle concentration of BMP-2, 1 week after surgery, with no newly formed bone tissue present. (b) Low concentration of incorporated BMP-7, 2 weeks after surgery: a rapid increase of newly formed bone tissue could be identified. (c) Low concentration of incorporated BMP-7, 3 weeks post-operatively: larger volumes of newly formed bone tissue were present. Thick sections $(80 \mu \mathrm{m})$, surface-stained using McNeil's tetrachrome and acid fuchsin. Scale bars: $200 \mu \mathrm{m}$. lowest concentration; the efficacy of BMP-7 in this group was found to be roughly 65 to 170 times higher than in the other BMP-7 groups.

\section{Systematic morphology and adverse effects}

Systematic histological analyses were performed throughout and around the implants (i.e. in close vicinity; Fig. 2,4) and in distant regions (i.e. to the natural mandibular/maxillar border in the buccomedial direction; see Materials and Methods section). Systematic serial vertical sectioning generally provided 4 parallel sections per tissue block and were scanned at higher magnifications. This scanning analysis revealed no evidence of any BMP-7-induced adverse effects at, near or distant to the implantation sites. In particular, unwanted effects such as cyst formation, local tissue swellings, ectopic ossification, immunological responses, malignant cell transformation, etc. (Faundez et al., 2016; Hudolin et al., 2020; Malham et al., 2015) were not found.

\section{Discussion}

New bone-tissue formation in the implant chamber under an osteopenic condition [as a paradigm for any state of local lack of bone tissue (such as osteoporosis, atrophy etc.) or impaired angiogenesis (which is associated with reduced formation of new bone tissue)] was impressively accelerated in the second post-operative week and it attained a large new bone volume by the lowest concentration of BMP7 delivered by the slow drug-release system. The narrow span of BMP-7 concentrations found to yield optimal results (compared to higher concentrations in the slow-release system and/or to adsorbed BMP-7 at slightly higher concentrations) nicely illustrated the importance of a strict control of drug concentration, which is needed for a safe and efficient BMP-7 use; otherwise, the desired effects may not be achieved or may even be counteracted. Even though a few experimental groups were associated with the formation of new bone tissue at a similar level and on a similar time scale to that of the low-concentrationincorporated group, the important fact to be noted was that when the growth factor was sequestered away from the many implant-surrounding different cell populations (as is the case when using a slowrelease system), the danger of unwanted side effects was indeed minimal. Moreover, if the growth factor is not incorporated in a slow-release system, the reservoir of the drug would be exhausted as rapidly as e.g. in the surface-adsorbed growth factor pool or in a freely applied mode of delivery [as is done presently in clinical practice (Burkus et al., 2003; Sierra-Garcia et al., 2016)]. In addition, a sustained release over time from a confined compartment not only assures a long-term ongoing osteogenic activity, but also provides maximum efficacy (being the delivery system directed specifically to the targeted cell pools) as well as mimics the physiological mode 
of growth factor release from the bone matrix during bone remodelling (Liu et al., 2018; Liu et al., 2005).

Other approaches to deal with the enhancement and acceleration of bone formation and implant osseointegration under osteopenic/osteoporotic conditions have been described, such as the local delivery of BMP-4 (Lai et al., 2011), the use of injectable tricalcium phosphate (TCP)-microspheres associated with BMP-2 (Chang et al., 2017), the local application of anti-cytokine antibodies (Yang et al., 2020) or the use of systemic sclerostin antibody treatment (Korn et al., 2019; Virdi et al., 2015). Another approach suggested relates to the presurgical injection of BMP-7 in a slow-release system [polyglycolic acid (PLGA)-microspheres] to initially build up local bone structure before implant placement (Phillips et al., 2006).

The concentration of BMP-7 identified in the present study for a maximum efficacy $(\approx 30 \mu \mathrm{g}$ BMP$7 / g$ carrier material) and for maximum osteogenicity (i.e. the largest volumes of new peri-implant bone tissue) was of the same order of magnitude as found by Hunziker et al. (2016) for BMP-2. BMP-2 was tested in sheep bones in vivo in a normal bony environment, using thick titanium-mesh implants for deep implant anchoring to the bone (such as cups of hip prostheses, etc.). The reason for this could be that both growth factors (BMP-2 and BMP7) were used at a very low dose, in the order of magnitude of BMPs' physiological concentrations, as stored in the healthy bone matrix. Such doses are physiologically released by a cell-mediated process during normal bone remodelling activities, during bone healing events such as bone fractures or healing of artificially created bone wound surfaces, such as during implant placement. In addition, the high degree of BMP-based osteogenicity may be due to the mechanism of release associated with such a CaP-based carrier matrix, simulating a native bone matrix from which the growth factor is released on a cell-mediated basis (Liu et al., 2018). Thus, the simulation of a physiological-like cell-mediated $\mathrm{BMP}$ release mode may be associated with a much higher efficacy than when applied therapeutically as a free factor or simply as an adsorbed factor to a carrier - which is in neither case a physiological mode. Moreover, by slow releasing the growth factor, the targeted cell pool is specifically the one involved in osteogenesis and the drug is not dispersed omnidirectionally onto different cell pools not involved in osteogenesis, but it remains confined and specifically exposed to the osteogenic cell-pool niche. Given the fact that this growth factor is highly pleiomorphic by its very nature, i.e. it is able to simultaneously induce both bone resorption and bone formation, its concentration in the physiological environment at a near-physiological level may be the key factor in the intrinsic decision to tipping the balance either towards a resorption activity (catabolic) or towards a formation activity (anabolic) (Herberg et al., 2014; Hunziker et al., 2016; Pobloth et al., 2017). Thus, the general problems associated with the clinical use of

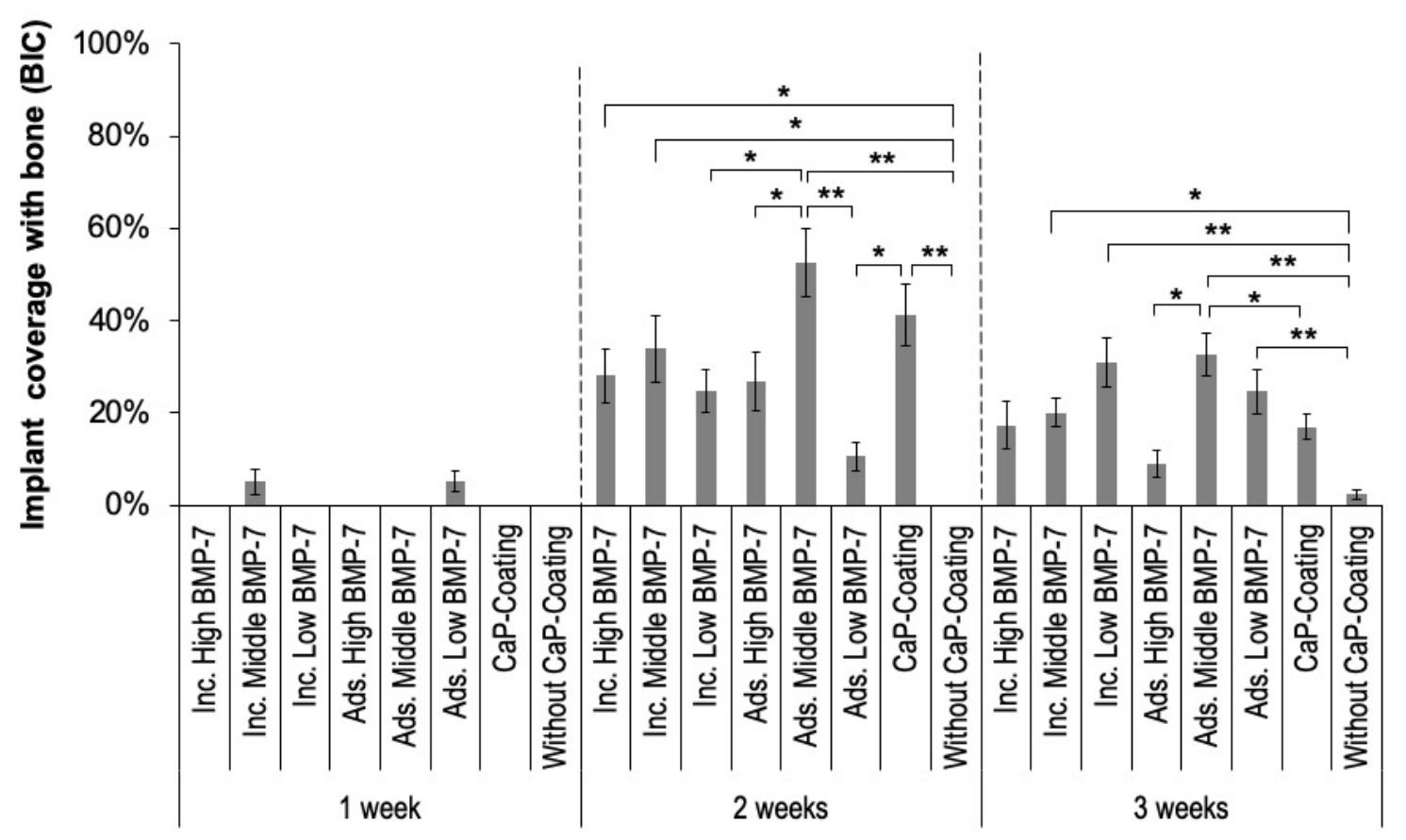

Fig. 5. Bone-to-implant contact proportions (BIC-values) in the various groups at the 3 time points investigated are represented. 1 week after surgery, all BIC-values obtained were very low. 2 weeks after surgery, the groups with the adsorbed (Ads.) middle BMP-7 concentration and the CaP-control group without any BMP-7 showed the highest BIC values. 3 weeks after surgery, the groups with the incorporated (Inc.) BMP-7 at low concentration and the group with the adsorbed middle concentration of BMP-7 showed the highest BIC-values. Mean values \pm SEM are represented . ${ }^{*} p<0.05,{ }^{* *} p<0.01$. 
this growth factor are indeed associated with its use at unphysiological high dosages at which it is generally applied (mg-levels) and the unphysiological mode by which it is exposed to the complex body cellular environment, i.e. to a variety of cell pools not involved in osteogenesis, both under physiological (normal bone) or pathological (osteoporosis, osteopenia, metabolic bone diseases, fractures, etc.) conditions.

Another aspect to be pointed out by using such a slow drug-release system is the fact that this drug carrier system has a thickness/mass that can be modulated (Liu et al., 2006b) to have longer degradation times and, thus, longer release and osteogenic induction times, if desired (Liu et al., 2018). This property could be a practical necessity, in particular when used under osteoporotic or osteopenic conditions or in situations where extensive bone augmentation is a clinical need. Also, in situations where a very long-lasting mechanical stability is needed to be actively induced such as, for example, under osteoporotic conditions where a long-lasting local anabolic osteogenic effect would be very welcome. Such possibilities render the $\mathrm{CaP}$ based drug carrier system particularly versatile and flexible to satisfy disease-specific needs.

The focus of the present study was intentionally set towards the new peri-implant bone volume formed rather than on the BIC parameter, i.e. the surface coverage of the implant with a thin layer of bone tissue. This latter phenomenon is primarily the result of and associated with a high degree of implant surface osteoconductive property (Liu et al., 2007). The firm and rapid anchoring of the implant requires a bridging of the whole implant surface to the native bone surface distant (peripheral) to it. It is this gap space that needs to be filled as rapidly and as evenly as possible with newly formed bone for the purpose of effective load force transmission from the implant to the native bone structure during implant loading activity. Only the presence of such bony bridging masses can provide a solid and firm secondary stability outcome for the implant (Bianchi et al., 2005; Cozzolino et al., 2019; Kopp et al., 2011). The mere coverage of the implant surface by a thin layer of bone tissue (as generally described by the BIC parameter), which is due to high osteconductive surface properties, is indeed insufficient in providing the necessary anchoring and functional osseointegration for a required biomechanical competence of the whole implant. The required rapid and homogenous gap-bridging by newly formed bone tissue between the native bone surface and the implant surface can be assessed only by measuring the newly formed bone tissue volume in this gap [and not by a simple parameter such as BIC (Hunziker et al., 2018), which unfortunately is often used in various studies relating to implant integration, with its biological meaningfulness thus overinterpreted]. The importance of a mechanically firm and even osseous connectivity between the implant surface and the surrounding native bone surfaces, in the orthopaedic implant development

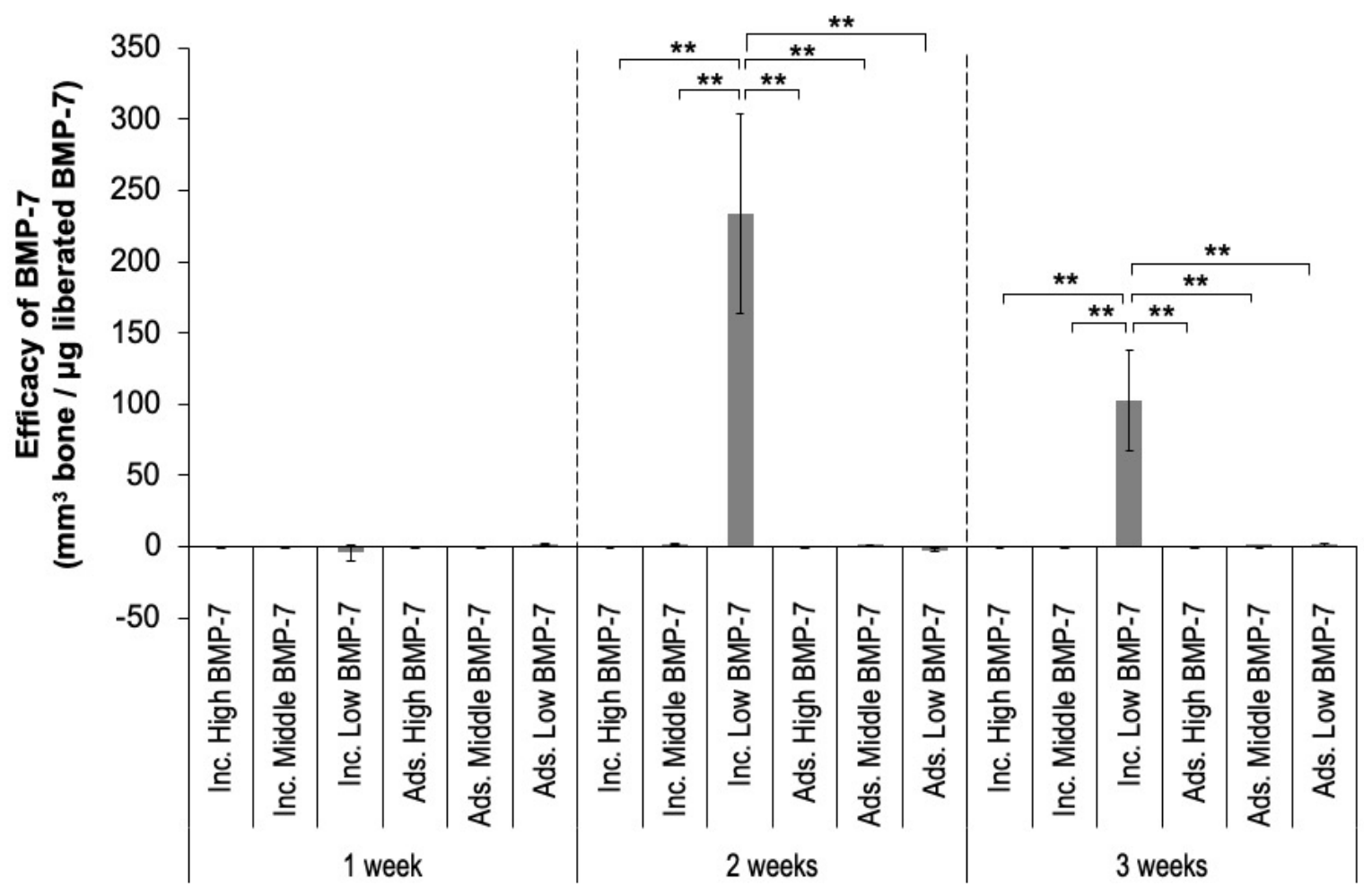

Fig. 6. Computed efficacy of BMP-7, defined as new bone volume generated per $\mu$ g liberated BMP-7. Only 2 weeks after surgery a measurable efficacy was observed, with the incorporated (Inc.) low concentration BMP-7 group showing the highest efficacy values, compared to all remaining groups. Mean values \pm SEM are represented. ${ }^{* *} p<0.01$. Ads.: adsorbed. 
process, was realised several decades ago when Bill Harris coined the term "osteogenic jumping distance" (Harris et al., 1983), which is nowadays called "critical gap healing distance" between native bone and implant surface (Alierta et al., 2014; Botticelli et al., 2003; Moreo et al., 2009).

It is not surprising that the osteoconductive surface properties that govern the BIC effects are independent of the presence and/or absence of BMP7. It is the CaP surface itself that is able to enhance the osteoconductive effects alone (and improve BIC values), as previously shown (Liu et al., 2007). But, unfortunately not enough attention is paid to the fact that the space between implant surfaces and native bone surfaces needs to be filled very rapidly, which can be quite challenging in particular under pathological conditions of insufficient bone tissue density (osteoporosis, osteopenia, etc.) or under conditions of angiogenesis problems, such as under nicotine abuse, diabetes etc.. The data of the present study reconfirmed previous findings: an implant surface with an enhanced osteoconductive property yields higher BIC values than simple SLA-titanium surfaces and the presence of BMPs additionally improves the peri-implant bone volume generated over just a simply enhanced osteoconductive surface property (Liu et al., 2007).

The systematic histological analyses of the periimplant tissues close to and also distant from the implant surfaces (Fig. 2,4) revealed no evidence of any BMP-7-induced adverse effects at or near the implant sites. Unwanted effects such as cyst formation, tissue swelling, ectopic ossification, etc. (Krishnakumar et al., 2017) were not observed. This most likely related to the relatively low concentrations of BMP used in all test groups; even those with a higher concentration of BMP and when used in an adsorbed form to the implant or carrier surfaces showed no complications of this type [since these concentrations were still orders of magnitude lower than what is applied in clinical practice (Pobloth et al., 2017)]. Indeed, in clinical practice, where various types of unwanted effects are observed, these are consistently associated with the use of BMPs on a mg-dosage level (Pobloth et al., 2017). In addition, the growth factors remained sequestered away from the various cell pools not involved in osteogenesis by using a delayed drugrelease system. Such a system confines them spatially and the factor is released on a cell-mediated basis (Liu et al., 2018) and, hence, is targeted to the desired osteogenesis-related cell pools.

Several limitations of the ruminant-animal model cannot be avoided since they are inherent to this model and relate to an immediate implant-loading scheme after surgery, combined with an exposure to high local masticatory stress forces (that cannot be avoided either). Thus, it was no surprise that 8 implants showed an insufficient primary stability (as defined by the criteria described in the Materials and Methods section). The reduced primary implant stability in an osteoporotic bone environment certainly has also contributed to this loss of implants. Moreover, in adult goats, local post-operative dental hygiene is not possible (for practical reasons) and, thus, 6 implants were found to show local infections. These contaminated implants as well as the mechanically unstable implants were excluded from the analysis. Also 3 animals were lost due to acute lethal diseases of unknown origin.

There is no doubt that this animal model has its disadvantages as these losses of implants do point out. However, what would be the alternative? The induction of osteoporosis in adult sheep (or dogs) is medically quite an aggressive procedure, including ovariectomy and steroid hormone application over several months, such as is done in the well-known osteoporosis sheep model (Kielbowicz et al., 2016; Zhang et al., 2016). Moreover, this model requires a preparation time of almost one year that would render the study extremely expensive, but also introduce some changes in the body physiology [absence of the normal female sex hormones, depression of metabolism due to chronic steroid application, model-induced impaired bone formation capabilities (Egermann et al., 2005; Zhang et al., 2016)] that would limit the conclusion potential of the study. Thus, this physiological model of local osteopenia (structurally appearing as in osteoporosis) was assumed to be useful since little secondary changes to the general metabolism were operating when compared to the experimentally induced animal models for osteoporosis.

\section{Conclusion}

BMP-7 was found to be a highly efficacious drug in actively promoting and accelerating the formation of new bone in the peri-implant space in a hostile osteopenic environment if released slowly over time at near-physiological concentrations. The use of a delayed drug-delivery system allowed for minimalisation of the required osteogenic growth factor dosage and was able to prevent untoward sideeffects (ectopic bone formation, inflammation, cyst formation etc.) by warding off the bioactive agent and, thus, significantly enhancing the safety of this drug.

\section{Acknowledgements}

The authors are grateful to Jianfeng He for his help with the morphometric analysis and to Prof. Zhiyuan $\mathrm{Gu}$ for his help with the surgery. Financial support for the study was obtained from the Foundation of Osteoporosis of the Clinic of Osteoporosis, Inselspital Bern University Hospital, Bern, Switzerland, from Stryker Corporation, Mahwah, NJ, USA (donation of BMP-7) and from the ITI Research Foundation, Basel, Switzerland. The funders had no role in study design, data collection and analysis, decision to publish and the preparation of the manuscript. 
The authors declare that they have no conflict of interest.

\section{References}

Alierta JA, Perez MA, Garcia-Aznar JM (2014). An interface finite element model can be used to predict healing outcome of bone fractures. J Mech Behav Biomed Mater 29: 328-338.

Alonso N, Calero-Paniagua I, Del Pino-Montes J (2017) Clinical and genetic advances in paget's disease of bone: a review. Clin Rev Bone Miner Metab 15: 37-48.

Ananth H, Kundapur V, Mohammed HS, Anand M, Amarnath GS, Mankar S (2015) A review on biomaterials in dental implantology. Int J Biomed Sci 11: 113-120.

Benn A, Hiepen C, Osterland M, Schutte C, Zwijsen A, Knaus P (2017) Role of bone morphogenetic proteins in sprouting angiogenesis: differential BMP receptor-dependent signaling pathways balance stalk vs. tip cell competence. FASEB J 31: 4720-4733.

Bertl K, Heimel P, Rokl-Riegler M, Hirtler L, Ulm C, Zechner W (2015) MicroCT-based evaluation of the trabecular bone quality of different implant anchorage sites for masticatory rehabilitation of the maxilla. J Craniomaxillofac Surg 43: 961-968.

Bianchi AE, Dolci G, Jr., Sberna MT, Sanfilippo S (2005) Factors affecting bone response around loaded titanium dental implants: a literature review. J Appl Biomater Biomech 3: 135-140.

Bodalia PN, Balaji V, Kaila R, Wilson L (2016) Effectiveness and safety of recombinant human bone morphogenetic protein-2 for adults with lumbar spine pseudarthrosis following spinal fusion surgery: A systematic review. Bone Joint Res 5: 145-152.

Bohner L, Hanisch M, Kleinheinz J, Jung S (2019) Dental implants in growing patients: a systematic review. Br J Oral Maxillofac Surg 57: 397-406.

Botticelli D, Berglundh T, Buser D, Lindhe J (2003) The jumping distance revisited: An experimental study in the dog. Clin Oral Implants Res 14: 35-42.

Burkus JK, Heim SE, Gornet MF, Zdeblick TA (2003) Is INFUSE bone graft superior to autograft bone? An integrated analysis of clinical trials using the LT-CAGE lumbar tapered fusion device. J Spinal Disord Tech 16: 113-122.

Caulier H, Vercaigne S, Naert I, van der Waerden JP, Wolke JG, Kalk W, Jansen JA (1997) The effect of Ca-P plasma-sprayed coatings on the initial bone healing of oral implants: an experimental study in the goat. J Biomed Mater Res 34: 121-128.

Chang AR, Cho TH, Hwang SJ (2017) Receptor activator of nuclear factor kappa-b ligand-induced local osteoporotic canine mandible model for the evaluation of peri-implant bone regeneration. Tissue Eng Part C Methods 23: 781-794.

Chen H, Liu N, Xu X, Qu X, Lu E (2013) Smoking, radiotherapy, diabetes and osteoporosis as risk factors for dental implant failure: a meta-analysis. PLoS One 8: e71955. DOI: 10.1371/journal.pone.0071955.

Cozzolino F, Apicella D, Wang G, Apicella A, Sorrentino R (2019) Implant-to-bone force transmission: a pilot study for in vivo strain gauge measurement technique. J Mech Behav Biomed Mater 90: 173-181.

de Queiroz Fernandes J, de Lima VN, Bonardi JP, Filho OM, Queiroz SBF (2018) Bone regeneration with recombinant human bone morphogenetic protein 2 : a systematic review. J Maxillofac Oral Surg 17: 13-18.

Egermann M, Goldhahn J, Schneider E (2005) Animal models for fracture treatment in osteoporosis. Osteoporos Int 16 Suppl : S129-138.

Faundez A, Tournier C, Garcia M, Aunoble S, Le Huec JC (2016) Bone morphogenetic protein use in spine surgery-complications and outcomes: a systematic review. Int Orthop 40: 1309-1319.

Gothard D, Smith EL, Kanczler JM, Rashidi H, Qutachi O, Henstock J, Rotherham M, El Haj A, Shakesheff KM, Oreffo RO (2014) Tissue engineered bone using select growth factors: A comprehensive review of animal studies and clinical translation studies in man. Eur Cell Mater 28: 166-207.

Gruber R, Weich HA, Dullin C, Schliephake H (2009) Ectopic bone formation after implantation of a slow release system of polylactic acid and rhBMP-2. Clin Oral Implants Res 20: 24-30.

Gundersen HJ, Bendtsen TF, Korbo L, Marcussen N, Møller A, Nielsen K, Nyengaard JR, Pakkenberg B, Sørensen FB, Vesterby A, West MJ (1988) Some new, simple and efficient stereological methods and their use in pathological research and diagnosis. APMIS 96: 379-394.

Gundersen HJ, Jensen EB (1987) The efficiency of systematic sampling in stereology and its prediction. J Microsc 147: 229-263.

Hammerle CHF, Tarnow D (2018) The etiology of hard- and soft-tissue deficiencies at dental implants: a narrative review. J Periodontol 89 Suppl 1: S291-S303.

Harris WH, White RE, Jr., McCarthy JC, Walker PS, Weinberg EH (1983) Bony ingrowth fixation of the acetabular component in canine hip joint arthroplasty. Clin Orthop Relat Res: 7-11.

Hasanoglu Erbasar GN, Hocaoglu TP, Erbasar RC (2019) Risk factors associated with short dental implant success: a long-term retrospective evaluation of patients followed up for up to 9 years. Braz Oral Res 33: e030. DOI: 10.1590/1807-3107bor-2019. vol33.0030.

Hauschka PV, Chen TL, Mavrakos AE (1988) Polypeptide growth factors in bone matrix. Ciba Found Symp 136: 207-225.

Hauschka PV, Mavrakos AE, Iafrati MD, Doleman SE, Klagsbrun M (1986) Growth factors in bone matrix. Isolation of multiple types by affinity chromatography on heparin-Sepharose. J Biol Chem 261: 12665-12674.

He YX, Zhang G, Pan X-H, Liu Z, Zheng L-Z, Chan C-W, Lee K-M, Cao Y-P, Li G, Wei L, Hung L-K, Leung K-S, Qin L (2011) Impaired bone healing pattern in 
mice with ovariectomy-induced osteoporosis: a drillhole defect model. Bone 48: 1388-1400.

Herberg S, Susin C, DDS, Pelaez M, Howie N, Moreno de Freitas R, Lee J, Cray JJ Jr, Johnson MH, Elsalanty ME, Hamrick MW, Isales CM, Wikesjö, Hill WD (2014) Low-dose bone morphogenetic protein-2/ stromal cell-derived factor-1beta cotherapy induces bone regeneration in critical-size rat calvarial defects. Tissue Eng Part A 20: 1444-1453.

Hudolin T, Kastelan Z, El-Saleh A, Bakula M, Coric M, Kes P, Tomas D, Basic-Jukic N (2020) Bone morphogenic proteins-2, $-4,-6$ and 7 in non-muscle invasive bladder cancer. Oncol Lett 19: 1291-1297.

Hunziker EB, Jovanovic J, Horner A, Keel MJ, Lippuner K, Shintani N (2016) Optimisation of BMP-2 dosage for the osseointegration of porous titanium implants in an ovine model. Eur Cell Mater 32: 241256.

Hunziker EB, Kapfinger E, Geiss J (2007) The structural architecture of adult mammalian articular cartilage evolves by a synchronized process of tissue resorption and neoformation during postnatal development. Osteoarthritis Cartilage 15: 403-413.

Hunziker EB, Spiegl-Habegger M, Rudolf S, Liu Y, Gu Z, Lippuner K, Shintani N, Enggist L (2018) A novel experimental dental implant permits quantitative grading of surface-property effects on osseointegration. Int J Oral Maxillofac Implants 33: 967-978.

James AW, LaChaud G, Shen J, Asatrian G, Nguyen V, Zhang X, Ting K, Soo C (2016) A review of the clinical side effects of bone morphogenetic protein-2. Tissue Eng Part B Rev 22: 284-297.

Jude EB, Eleftheriadou I, Tentolouris N (2010) Peripheral arterial disease in diabetes-a review. Diabet Med 27: 4-14.

Kielbowicz Z, Piatek A, Kuropka P, Mytnik E, Nikodem A, Biezynski J, Skrzypczak P, Pezowicz C, Kuryszko J, Reichert P (2016) Experimental osteoporosis in sheep-mechanical and histological approach. Pol J Vet Sci 19: 109-118.

Kopp S, Kuzelka J, Goldmann T, Himmlova L, Ihde $S$ (2011) Modeling of load transmission and distribution of deformation energy before and after healing of basal dental implants in the human mandible. Biomed Tech (Berl) 56: 53-58.

Korn P, Kramer I, Schlottig F, Tödtmann N, Eckelt U, Bürki A, Ferguson SJ, Kautz A, Schnabelrauch M, Range U, Kneissel M, Stadlinger B (2019) Systemic sclerostin antibody treatment increases osseointegration and biomechanical competence of zoledronic-acid-coated dental implants in a rat osteoporosis model. Eur Cell Mater 37: 333-346.

Kowalczewski CJ, Saul JM (2018) Biomaterials for the delivery of growth factors and other therapeutic agents in tissue engineering approaches to bone regeneration. Front Pharmacol 9: 513. DOI: 10.3389/ fphar.2018.00513

Krishnakumar GS, Roffi A, Reale D, Kon E, Filardo G (2017) Clinical application of bone morphogenetic proteins for bone healing: a systematic review. Int Orthop 41: 1073-1083.

Kullar AS, Miller CS (2019) Are there contraindications for placing dental implants? Dent Clin North Am 63: 345-362.

Lai YL, Kuo NC, Hsiao WK, Yew TL, Lee SY, Chen HL (2011) Intramarrow bone morphogenetic protein 4 gene delivery enhances early implant stability in femurs of ovariectomized rabbits. J Periodontol 82: 1043-1050.

Linkhart TA, Mohan S, Baylink DJ (1996) Growth factors for bone growth and repair: IGF, TGF beta and BMP. Bone 19: 1S-12S.

Liu HW, Chen CH, Tsai CL, Hsiue GH (2006a) Targeted delivery system for juxtacrine signaling growth factor based on rhBMP-2-mediated carrierprotein conjugation. Bone 39: 825-836.

Liu Y, Enggist L, Kuffer AF, Buser D, Hunziker EB (2007) The influence of BMP-2 and its mode of delivery on the osteoconductivity of implant surfaces during the early phase of osseointegration. Biomaterials 28: 2677-2686.

Liu Y, Li JP, Hunziker EB, de Groot K (2006b) Incorporation of growth factors into medical devices via biomimetic coatings. Philos Trans A Math Phys Eng Sci 364: 233-248.

Liu Y, Schouten C, Boerman O, Wu G, Jansen JA, Hunziker EB (2018) The kinetics and mechanism of bone morphogenetic protein 2 release from calcium phosphate-based implant-coatings. J Biomed Mater Res A 106: 2363-2371.

Liu YM, de Groot K, Hunziker EB (2005) Cellmediated protein release from calcium-phosphatecoated titanium implants. J Control Release 101: 346-347.

Maisani M, Sindhu KR, Fenelon M, Siadous R, Rey S, Mantovani D, Chassande O (2018) Prolonged delivery of BMP-2 by a non-polymer hydrogel for bone defect regeneration. Drug Deliv Transl Res 8: 178-190.

Malham GM, Giles GG, Milne RL, Blecher CM, Brazenor GA (2015) Bone morphogenetic proteins in spinal surgery: what is the fusion rate and do they cause cancer? Spine (Phila Pa 1976) 40: 1737-1742.

Moreo P, Garcia-Aznar JM, Doblare M (2009) Bone ingrowth on the surface of endosseous implants. Part 2: Theoretical and numerical analysis. J Theor Biol 260: 13-26.

Nam JW, Khureltogtokh S, Choi HM, Lee AR, Park YB, Kim HJ (2017) Randomised controlled clinical trial of augmentation of the alveolar ridge using recombinant human bone morphogenetic protein 2 with hydroxyapatite and bovine-derived xenografts: comparison of changes in volume. $\mathrm{Br} \mathrm{J}$ Oral Maxillofac Surg 55: 822-829.

Naujokat H, Kunzendorf B, Wiltfang J (2016) Dental implants and diabetes mellitus-a systematic review. Int J Implant Dent 2: 5. DOI: 10.1186/s40729016-0038-2. 
Obalum DC, Eyesan SU, Fiberesima F, Ogo CN, Nzewi C, Mijinyawa M (2013) Perioperative considerations in orthopaedic patients with diabetes mellitus: a review. Niger Postgrad Med J 20: 223-227.

Pauletto P, Ruales-Carrera E, Goncalves T, Philippi AG, Donos N, Mezzomo LA (2019) Fixed and removable full-arch restorations supported by short $(\leq 8-\mathrm{mm})$ dental implants in the mandible: a systematic review and meta-analysis. Int J Oral Maxillofac Implants 4: 873-885.

Pearl SH, Kanat IO (1988) Diabetes and healing: a review of the literature. J Foot Surg 27: 268-270.

Pearson HB, Mason DE, Kegelman CD, Zhao L, Dawahare JH, Kacena MA, BoerckelJD (2019) Effects of bone morphogenetic protein-2 on neovascularization during large bone defect regeneration. Tissue Eng Part A 25: 1623-1634.

Phillips FM, Turner AS, Seim HB, 3rd, MacLeay J, Toth CA, Pierce AR, Wheeler DL (2006) In vivo BMP-7 (OP-1) enhancement of osteoporotic vertebral bodies in an ovine model. Spine J 6: 500-506.

Pirc M, Dragan IF (2017) The Key points of maintenance therapy for dental implants: a literature review. Compend Contin Educ Dent 38: e5-e8.

Pobloth AM, Duda GN, Giesecke MT, Dienelt A, Schwabe P (2017) High-dose recombinant human bone morphogenetic protein-2 impacts histological and biomechanical properties of a cervical spine fusion segment: results from a sheep model. J Tissue Eng Regen Med 11: 1514-1523.

Radi IA, Ibrahim W, Iskandar SMS, AbdelNabi N (2018) Prognosis of dental implants in patients with low bone density: a systematic review and metaanalysis. J Prosthet Dent 120: 668-677.

Shim JY, Lee Y, Lim JH, Jin MU, Lee JM, Suh JY, Kim YG (2018) Comparative evaluation of recombinant human bone morphogenetic protein-2/ hydroxyapatite and bovine bone for new bone formation in alveolar ridge preservation. Implant Dent 27: 623-629.

Sierra-Garcia GD, Castro-Rios R, Gonzalez-Horta A, Lara-Arias J, Chavez-Montes A (2016) [Bone morphogenetic proteins (BMP): clinical application for reconstruction of bone defects]. Gac Med Mex 152: 381-385.

Teng FY, Tai IC, Ho ML, Wang JW, Weng LW, Wang YJ, Wang MW, Tseng CC (2019) Controlled release of BMP-2 from titanium with electrodeposition modification enhancing critical size bone formation. Mater Sci Eng C Mater Biol Appl 105: 109879. DOI: 10.1016/j.msec.2019.109879.

Venkatesan N, Liyanage ADT, Castro-Nunez J, Asafo-Adjei T, Cunningham LL, Dziubla TD, Puleo DA (2019) Biodegradable polymerized simvastatin stimulates bone formation. Acta Biomater 93: 192-199.

Virdi AS, Irish J, Sena K, Liu M, Ke HZ, McNulty MA, Sumner DR (2015) Sclerostin antibody treatment improves implant fixation in a model of severe osteoporosis. J Bone Joint Surg Am 97: 133-140.

Yang F, Zhang X, Huang H, Wu G, Lippuner K, Hunziker EM (2020) Anti-cytokine activity enhances osteogenesis of bioactive implants. Tissue Eng Part A. DOI: 10.1089/ten.TEA.2020.0067.

Zhang Z, Ren H, Shen G, Qiu T, Liang, Yang Z, Yao Z, Tang J, Jiang X, Wei Q (2016) Animal models for glucocorticoid-induced postmenopausal osteoporosis: An updated review. Biomed Pharmacother 84: 438-446.

\section{Web Reference}

1. www.goatworld.com/articles/nutrition/ sheepgoatnutrition [28-01-2021]

\section{Discussion with Reviewers}

Piefrancesco Pagella: Did the authors observe alterations in the degree of vascularisation or immune reaction in response to the different experimental conditions?

Authors: The authors verified only morphologically if any cell-based unwanted immune responses were present and such responses were not found. Humoral and other blood-borne immunological analyses were not performed. Moreover, possible different degrees of vascularisation in the different experimental groups at the end of the experiment were not studied. Indeed, this may be an interesting aspect to be investigated and may help to reinforce data interpretation. It is also clear that since in all experimental groups the same type of animals were used, no differences in vascularisation could be expected at the onset of the experiments. And since newly formed bone tissue is always associated with the presence of blood vessels (it is a precondition of bone tissue formation), in the experimental groups with larger bone volume densities at the end of the experiment also the associated blood vasculature was increased in parallel.

The experimental set up was designed to investigate the possible enhancement of the process of new bone formation in the early phase of healing of dental implants under osteopenic conditions. To study the healed implant maintenance duration and the long-term survival, a full new study would need to be performed.

Editor's note: The Scientific Editor responsible for this paper was Thimios Mitsiadis. 